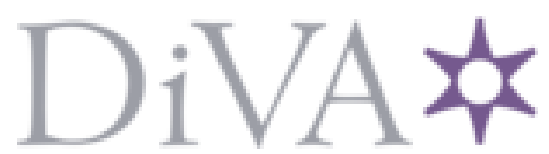

http://www.diva-portal.org

This is the published version of a paper published in Journal of Applied Physics.

Citation for the original published paper (version of record):

Engström, J., Eriksson, M., Isberg, J., Leijon, M. (2009)

Wave energy converter with enhanced amplitude response at frequencies coinciding with

Swedish west coast sea states by use of a supplementary submerged body.

Journal of Applied Physics, 106(6): 064512

http://dx.doi.org/10.1063/1.3233656

Access to the published version may require subscription.

N.B. When citing this work, cite the original published paper.

Copyright (2009) AIP Publishing. This article may be downloaded for personal use only. Any other use requires prior permission of the author and AIP Publishing. The following article appeared in Journal of Applied Physics 106, 064512 (2009) and may be found at http://dx.doi.org/10.1063/1.3233656

Permanent link to this version:

http://urn.kb.se/resolve?urn=urn:nbn:se:uu:diva-113142 


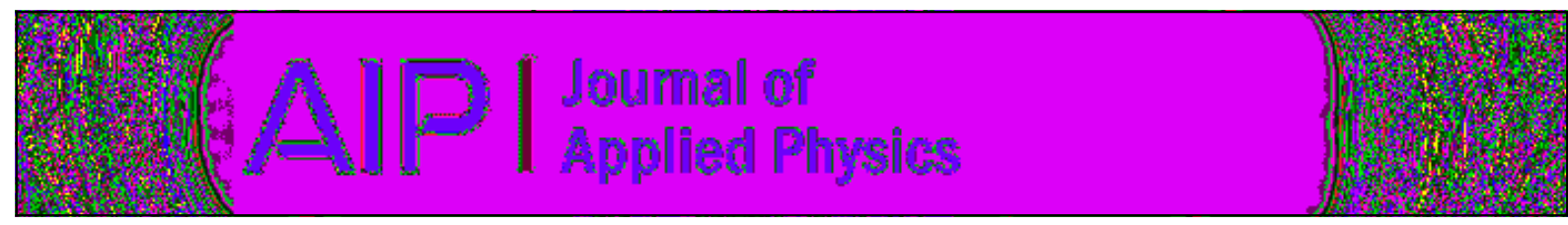

\section{Wave energy converter with enhanced amplitude response at frequencies coinciding with Swedish west coast sea states by use of a supplementary submerged body}

J. Engström, M. Eriksson, J. Isberg, and M. Leijon

Citation: Journal of Applied Physics 106, 064512 (2009); doi: 10.1063/1.3233656

View online: http://dx.doi.org/10.1063/1.3233656

View Table of Contents: http://scitation.aip.org/content/aip/journal/jap/106/6?ver=pdfcov

Published by the AIP Publishing

\section{Articles you may be interested in}

Wave characteristic analysis and wave energy resource evaluation in the China Sea

J. Renewable Sustainable Energy 6, 043101 (2014); 10.1063/1.4885842

Performance of large arrays of point absorbing direct-driven wave energy converters

J. Appl. Phys. 114, 204502 (2013); 10.1063/1.4833241

The dominant nonlinear wave interaction in the energy balance of a wind-driven sea

Low Temp. Phys. 36, 772 (2010); 10.1063/1.3499239

Predicting rogue waves in random oceanic sea states

Phys. Fluids 17, 031701 (2005); 10.1063/1.1872093

Extreme wave events in directional, random oceanic sea states

Phys. Fluids 14, L25 (2002); 10.1063/1.1453466

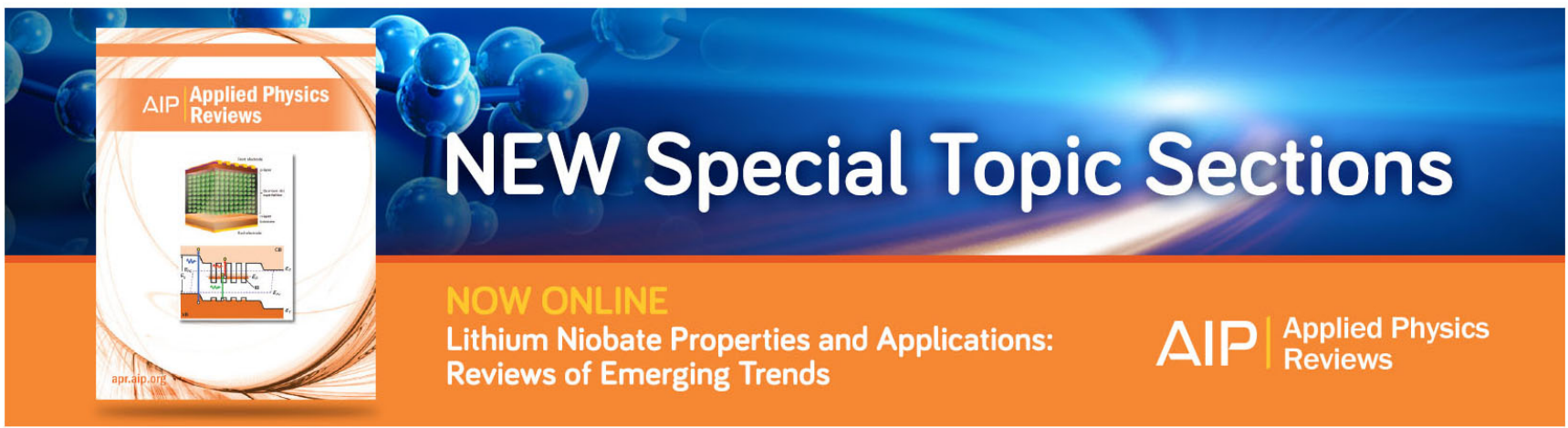




\title{
Wave energy converter with enhanced amplitude response at frequencies coinciding with Swedish west coast sea states by use of a supplementary submerged body
}

\author{
J. Engström, ${ }^{1, a)}$ M. Eriksson, ${ }^{2}$ J. Isberg, ${ }^{1}$ and M. Leijon ${ }^{1}$ \\ ${ }^{1}$ Department of Engineering Sciences, Swedish Centre for Renewable Electric Energy Conversion, Division \\ of Electricity, The Angström Laboratory, Uppsala University, Box 534, 75121 Uppsala, Sweden \\ ${ }^{2}$ Seabased Industry AB, Dag Hammarskjölds väg 52 B, SE-751 83 Uppsala, Sweden
}

(Received 26 January 2009; accepted 24 August 2009; published online 28 September 2009)

\begin{abstract}
The full-scale direct-driven wave energy converter developed at Uppsala University has been in offshore operation at the Swedish west coast since 2006. Earlier simulations have now been validated by full-scale experiment with good agreement. Based on that, a theoretical model for a passive system having optimum amplitude response at frequencies coinciding with Swedish west coast conditions has been developed. The amplitude response is increased by adding supplementary inertia by use of the additional mass from a submerged body. A sphere with neutral buoyancy is chosen as the submerged body and modeled as being below the motion of the waves. The model is based on potential linear wave theory and the power capture ratio is studied for real ocean wave data collected at the research test site. It is found that the power capture ratio for the two body system can be increased from $30 \%$ to $60 \%$ compared to a single body system. Increased velocity in the system also decreases the value for optimal load damping from the generator, opening up the possibility to design smaller units. (c) 2009 American Institute of Physics. [doi:10.1063/1.3233656]
\end{abstract}

\section{INTRODUCTION}

The untamed energy of the ocean waves contains power on the order of terawatts, with the same order of magnitude as the world electricity demands. ${ }^{1}$ Therefore, engineers have strived for a cost effective technology to convert the wave energy for human utilization. ${ }^{2}$ The concept of a point absorber converting the heaving motions of waves to electric energy has been one of the main concepts that have been investigated since the research begun. ${ }^{3-5}$ It is well understood that a point absorber in resonance with the incident wave will achieve increased amplitude and speed and thereby transfer more energy than a system working off resonance. ${ }^{5,6}$

Coasts facing the oceans are naturally the most attractive for wave energy conversion, coasts where the dominating sea state has wave periods of $T_{e}>5 \mathrm{~s}^{7}$ It is therefore desirable to have a wave energy converter (WEC) system tuned to have a natural period of oscillation that coincide with sea state at the site. Methods to force the system into resonance via active control were proposed by Budal and Salter independently in the mid-1970s. Budal later proposed the method to latch the point absorber at fixed positions and thereby achieve approximate phase control. ${ }^{8}$ Instead of an active control system, another strategy would be to somehow engineer the frequency response of the point absorber so as to have maximal wave interference with the dominant sea states at the chosen location. In addition, it may be desirable to keep the power capture ratio at low levels at extreme sea states that may arise during storms, to reduce the maximum loads

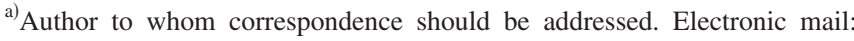
jens.engstrom@angstrom.uu.se. Tel.: +46 (0)18471 58 18. FAX: +46 (0)184715810.
}

on the system. One way of shifting the frequency response of the system is by increasing the inertia of the moving parts. This have led to the idea of a system of two objects, a semisubmerged object at the surface extracting energy, while the lower submerged object adds the desired inertia., ${ }^{9,10}$ Laboratory experiments with adjustable inertia have shown to give a $60 \%$ power capture ratio in irregular waves. ${ }^{3}$ The experiment was scaled to correspond to a measured spectra with significant wave heights of $H_{s} 1.0-1.5$, average wave periods of $T_{z} 3.5-4.5 \mathrm{~m}$, and a buoy with $5 \mathrm{~m}$ diameter.

The WEC concept named the Lysekil project that is being developed at Uppsala University is a direct-driven linear generator connected to a semisubmerged cylinder. ${ }^{11}$ A fullscale experimental prototype has been installed off the Swedish west coast. It has delivered power since 2006 and the results of earlier simulations have been confirmed. ${ }^{42-14}$ During the first period of offshore operation, a $1.5 \mathrm{~m}$ radius cylindrical buoy was used and absorbed power was measured over linear resistive loads with adjustable load values of $12.7,8.53$, and $5.23 \mathrm{kN} \mathrm{s} / \mathrm{m}$. This generator/buoy configuration achieved for the $12.7 \mathrm{kN} \mathrm{s} / \mathrm{m}$ load a maximum $30 \mathrm{~min}$ averaged power capture ratio of $24 \%$, excluding iron and mechanical losses, for energy periods around $4.5 \mathrm{~s}$ and a significant wave height of approximately $1.2 \mathrm{~m} .{ }^{15}$

This paper describes a WEC system of two objects connected to a linear damper, which in this case simulates the direct-driven linear generator (see Fig. 1). The first object is a semisubmerged cylinder, exposed to the wave energy. The second one, the sphere, will act as an additional mass submerged well below the motions of the ocean waves. The hydrodynamic coefficients of the semisubmerged cylinder have been calculated by a BEM code, and then convoluted with time series data of the wave elevation gathered by a 


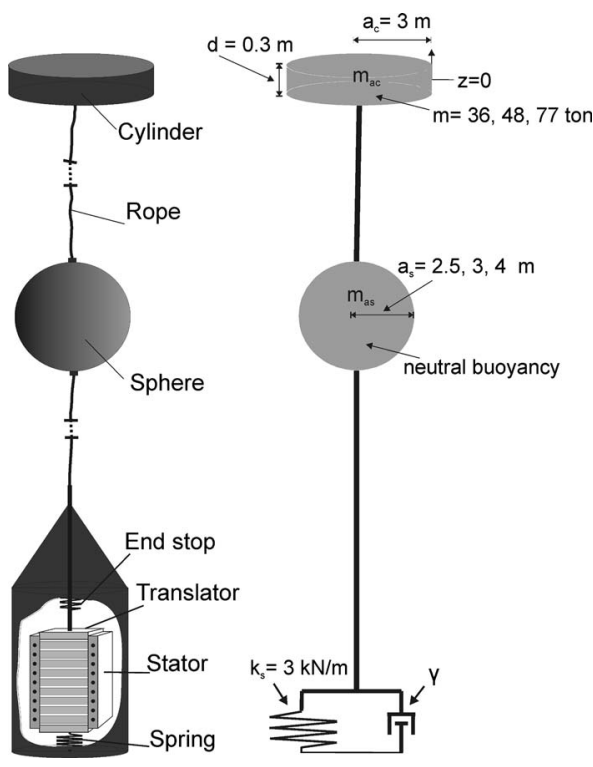

FIG. 1. A conceptual sketch of the Tb-s. Here $a_{c}$ is the radius of the semisubmerged cylinder, $d$ is the draft, $m_{a c}$ is the added mass for the cylinder, $a_{s}$ is the radius of the submerged sphere, $m$ is the total mass of the cylinder, sphere, and translator for each radius of the sphere, and $m_{a s}$ is the added mass for the sphere. $\gamma$ is the damping coefficient from the generator and $k_{s}$ is the spring constant. The figure is not to scale.

Waverider ${ }^{\mathrm{TM}}$ wave measurement buoy at the research test site. This model has been developed with the Lysekil project concept in mind with the main objective to compare the power production for a two body system (Tb-s) tuned to have an enhanced amplitude response at frequencies coinciding with the dominating sea state at the Swedish west coast, to the present system with a single semisubmerged cylinder.

\section{THEORY}

As the wave interacting part of a point absorber in this case, we consider a semisubmerged cylinder with radius $a_{c}$ and draft $d$. The connection between the semisubmerged cylinder and the linear generator is modeled as a stiff rod. Thus, we restrict the buoy motion from six degrees of freedom to heave only. The generator is modeled as a linear damper; i.e., the force is directly proportional to the velocity of the translator. The constant of proportionality is the load damping coefficient $\gamma$. The approach of a linear damper further assumes that the active length of the translator/stator is much longer than the stroke length of the translator; i.e., the damping is $100 \%$ active during the stroke length. A spring with a spring constant $k_{s}$ is attached to the translator acting as a restoring force. Between the cylinder and generator, there is a sphere of neutral buoyancy with radius $a_{s}$. The submerged sphere is modeled as being entirely below the motion of the waves.

Potential linear wave theory has previously been used to describe a point absorber working in heave only ${ }^{6,16}$ and the limitations of linear theory for this application has also been studied experimentally. ${ }^{17}$

Following this, the hydrodynamic force acting on the cylinder is described by

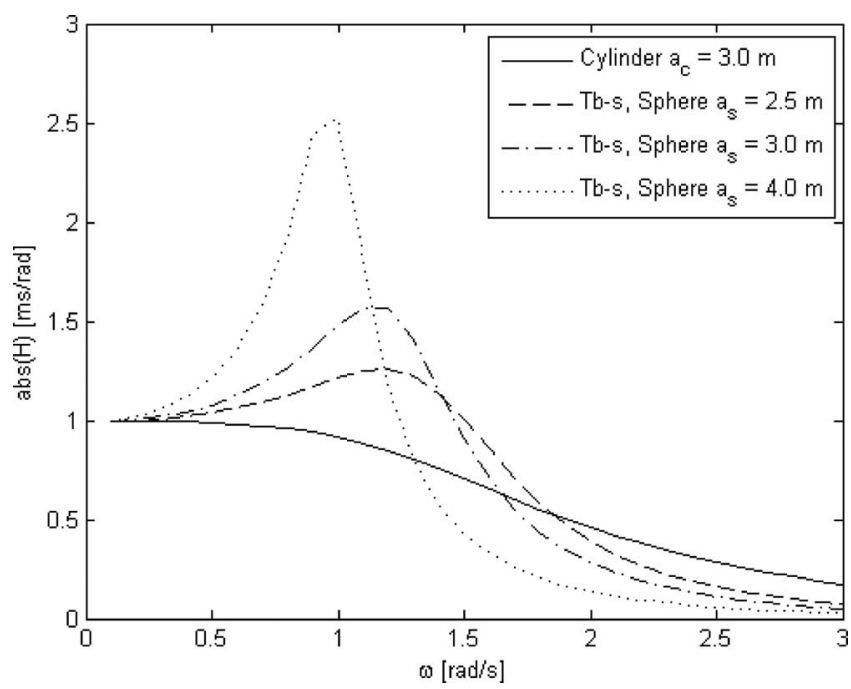

FIG. 2. The amplitude of the transfer function $\hat{H}$ as a function of angular frequency. The solid line shows the results for a single cylinder with $3 \mathrm{~m}$ radius, the other lines for the Tb-s with different radii of the sphere. The damping coefficient $\gamma$ is set to $60 \mathrm{kN} \mathrm{s} / \mathrm{m}$. With Tb-s; it means; Two Body System.

$$
F_{c}=F_{e}+F_{r}+F_{h},
$$

where $F_{e}$ is the force describing the excitation problem, $F_{r}$ is the force associated with the radiation problem, and $F_{h}$ is the hydrostatic stiffness. For a system with a buoy coupled to a linear damper with a spring acting as a restoring force, the relation between the amplitude of the incoming wave and the buoy position can be described by

$$
\hat{z}=\hat{H}(\omega) \hat{\eta}(\omega),
$$

where

$$
\hat{H}(\omega)=\frac{\hat{f}_{e}}{-\omega^{2}\left(m_{a c}+m+m_{a s}\right)+i \omega(\gamma+R)+\rho \pi g a_{c}^{2}+k_{s}} .
$$

Here $\hat{H}$ is a transfer function describing the relation between the amplitude of the incoming undisturbed wave $\hat{\eta}$ and the buoy position $\hat{z}$. The hydrodynamic parameters added mass $m_{a c}$, radiation resistance $R$, and the excitation force $\hat{f}_{e}$ are calculated using a BEM code. ${ }^{18}$ The absolute value of $\hat{H}$ is plotted for the two different cases as a function of $\omega$, see Fig. 2. Equation (3) also contains information of the resonance frequency of the system, which occurs when

$$
\omega=\sqrt{\frac{\rho g \pi a_{c}^{2}+k_{s}}{m_{a c}+m+m_{a s}}} .
$$

One of the dominating factors affecting the resonance frequency for this system subjected to ocean waves is the buoy radius, both directly, see Eq. (4), and indirectly since the added mass $m_{a c}$ depends on the buoy radius. ${ }^{19}$ The dominating sea state at the Swedish west coast has an energy period $T_{e}$ between 4 and $7 \mathrm{~s}^{20}$ Earlier simulations show that for a damped oscillating system in heave with fixed mass for the moving parts, the natural period of oscillation in heave will not coincide with a characteristic wave spectrum of the 
Swedish west cost as long as the radius of the buoy are kept within a reasonable size, in this case $1-5 \mathrm{~m}$ radius. ${ }^{19}$ Furthermore, for an array of cylindrical buoys restricted to a finite area, a radius of about $3 \mathrm{~m}$ have been shown to give optimum annual power, for a sea state with an energy period of $7-8 \mathrm{s.}^{21}$ One way to decrease the frequency for optimum amplitude response is to increase the mass of the moving parts, see Eq. (4). By increasing the mass of the moving parts, the draft of the buoy inevitably increases. Since the energy density in the waves decreases rapidly with depth, it leads to a decrease in power capture ratio. Earlier simulations also show that the draft/radius ratio should be kept at a minimum. ${ }^{21}$ Regarding the spring constant $k_{s}$, it has to be dimensioned in accordance with the hydrostatic lift force in order to keep a pretension in the rope. By connecting the semisubmerged cylinder to an extra object with neutral buoyancy placed below the wave motion, one can take advantage of its inertia due to the object's added mass and own physical mass. The desired draft for the semisubmerged cylinder can be held since the extra object has neutral buoyancy. The combined system's increased inertia gives a decrease in frequency for optimum amplitude response, see Eq. (4). Since waves need a density interface to propagate, there will be no losses due to radiation resistance and that together with its neutral buoyancy makes the submerged object's only contribution an increased inertia in the system when accelerating.

As the submerged object, any shape could be chosen. A disk with the same radius as the sphere has a somewhat higher added mass. ${ }^{22}$ The disk also has the benefit of being flat, thereby occupying less space. However, a greater energy loss due to viscous dissipation may be expected due to the sharp edges of the disk. This is the reason for choosing the smooth sphere at this stage. The added mass for a sphere in a continuous medium with no boundaries can be written as ${ }^{22}$

$$
m_{a s}=\frac{2}{3} \pi \rho a_{s}^{3}
$$

By choosing the radius of the sphere, one can tune the Tb-s's frequency for maximum amplitude response to the energy period of the actual sea state, see Eqs. (4) and (5).

The buoy position $z$ in the time domain is found by taking the convolution of the impulse response function $H(t)$ with the wave amplitude $\eta(t)$.

$$
z(t)=H(t) \eta(t)
$$

The impulse response function $H(t)$ is found by applying the inverse Fourier transform to the transfer function $\hat{H}(\omega)$. The average power $\bar{P}$ absorbed by the buoy is found by taking the time average according to

$$
\bar{P}=\frac{1}{T} \int_{0}^{T} \gamma\left(\frac{d z}{d t}\right)^{2} d t
$$

where $T$ is the time interval under consideration. The power capture ratio is defined as the absorbed average power $\bar{P}$ divided by the incident power across the cross section of the buoy.

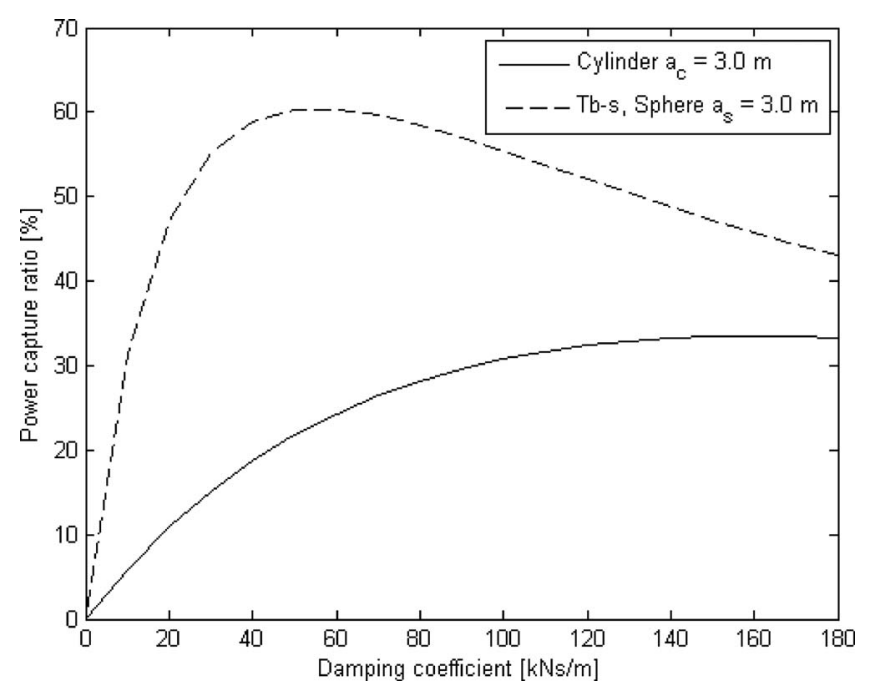

FIG. 3. Power capture ratio as a function of the damping coefficient $\gamma$. Sea state is a spectrum with $H_{s}=0.8 \mathrm{~m}$ and $T_{e}=4.5 \mathrm{~s}$. With Tb-s; it means; Two Body System.

$$
P_{\text {ratio }}=\frac{\bar{P}}{2 a_{c} \cdot J},
$$

where the incident energy flux $J$ is given by

$$
J=\frac{\rho g^{2}}{64 \pi} T_{e} H_{s}^{2} .
$$

Here $T_{e}$ is the energy period, $H_{s}$ is the significant wave height, $\rho$ is the density of sea water, and $g$ is the acceleration of gravity. In Eq. (9), the deep water approximation are used, which is a reasonable approximation when the water depth $H$ is much larger than the wavelength $\lambda$ or $H>0.28 \lambda .{ }^{23}$ Calculated values of $P_{\text {ratio }}$ for $30 \mathrm{~min}$ time series of wave elevation as a function of the load damping coefficient are presented in Fig. 3. $P_{\text {ratio }}$ at optimum damping for 34 different time series of measured sea states are presented in Fig. 4.

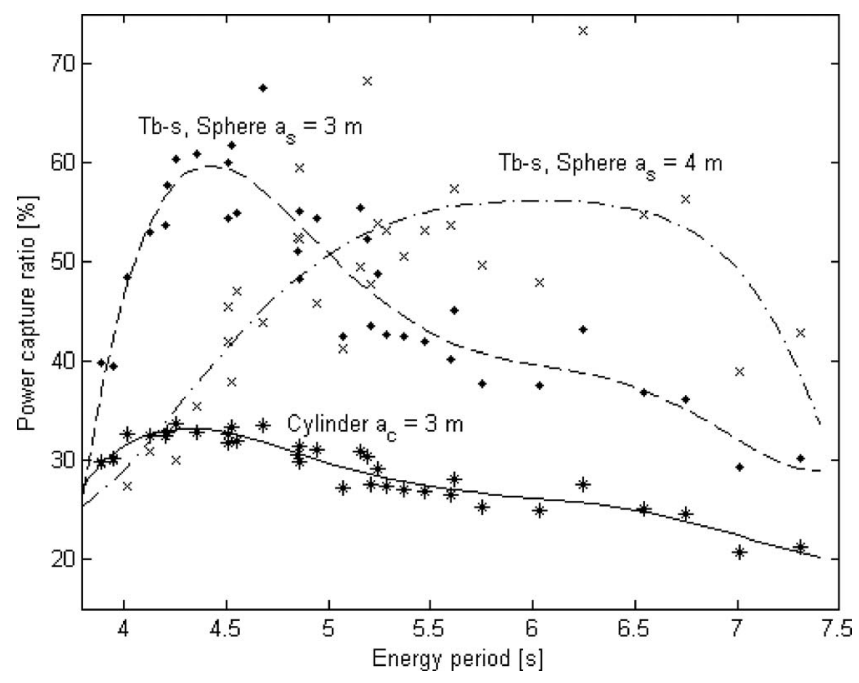

FIG. 4. Power capture ratio as a function of 34 different sea states at optimum damping. Each sea state is given in Table I. With Tb-s; it means; Two Body System. The lines are made as a guide for the eye. 
TABLE I. Significant wave height $H_{s}$ and energy period $T_{e}$ for the 34 sea states used to force the model.

\begin{tabular}{ll}
\hline \hline$T_{e}$ & \\
$(\mathrm{~s})$ & $H_{s}$ \\
$(\mathrm{~m})$
\end{tabular}

\section{SEA STATE}

The prevailing south westerly winds at the Swedish west coast give rise to an average energy flux of $5.2 \mathrm{~kW} / \mathrm{m}$ in offshore Skagerrak. When moving closer to shore, the energy flux decreases and at the research test site of Islandsberg it is measured to be $2.6 \mathrm{~kW} / \mathrm{m}$. A closer look reveals that most of the energy is found within energy periods of $4-7 \mathrm{~s} .{ }^{15,20} \mathrm{~A}$ Waverider ${ }^{\mathrm{TM}}$ wave measurement buoy that is located $50 \mathrm{~m}$ from the WEC continuously measures the sea state at the research test site. ${ }^{24} 30 \mathrm{~min}$ series of the wave elevation $\eta$ sampled with $2.56 \mathrm{~Hz}$ are collected. 34 different time series measured during January 2008 with energy periods that resemble the predominating sea state at the research test site have been selected and used to force the model. Power spectra for each time series are calculated and from this the energy period $T_{e}$ and significant wave height $H_{s}$ are calculated and used in Eq. (9). Here $T_{e}$ is defined as $m_{-1} / m_{0}$ and $H_{s}$ as $4 \sqrt{m_{0}}$, where $m_{n}$ is the $n$th spectral moment. Energy period and significant wave height for the 34 time series of wave elevation are presented in Table I.

\section{RESULTS}

The transfer function $\hat{H}$ relating the wave elevation and buoy position yields the dynamic response of the buoy to the wave motion, see Fig. 2. Increased amplitude of the buoy motion is desired since it gives higher power levels, see Eq. (7). The draft $d=0.3 \mathrm{~m}$ and the spring constant $k_{s}$ $=3 \mathrm{kN} / \mathrm{m}$ are kept constant throughout the calculations.

The solid line in Fig. 2 shows the absolute value of the transfer function $\hat{H}$ for a cylinder of $3 \mathrm{~m}$ radius. The load damping coefficient $\gamma$ strongly affects the magnitude of the peak response but has only a slight influence on the peak response frequency. For this reason, the load damping coefficient is held fixed at $60 \mathrm{kN} \mathrm{s} / \mathrm{m}$. The frequency for optimum amplitude response for the TB-s decreases with increasing radius of the sphere, see Fig. 2. It is desirable for efficient wave energy conversion to have a high hydrodynamic efficiency in a wide range of wave periods; this criterion is met for the Tb-s, as can be seen in Fig. 2. A Tb-s with a $3 \mathrm{~m}$ radius sphere has a maximum amplitude response at $5.2 \mathrm{~s}$, which coincides with the sea state of the Swedish west coast.

The power capture ratio for a cylinder with $3 \mathrm{~m}$ radius is about $32 \%$ for an optimum damping coefficient $\gamma$ of about $160 \mathrm{kN} \mathrm{s} / \mathrm{m}$. With an extra object added to the system, the power capture ratio can be increased to $60 \%$, with a decreased optimum damping coefficient of $60 \mathrm{kN} \mathrm{s} / \mathrm{m}$, as shown in Fig. 3.

The Tb-s with a $3 \mathrm{~m}$ radius sphere is tuned to have a maximum amplitude response at $5.2 \mathrm{~s}$, which is somewhat higher than the peak in power capture ratio for the Tb-s at $4.5 \mathrm{~s}$, see Fig. 4 . The $4 \mathrm{~m}$ radius sphere differs from the $3 \mathrm{~m}$ radius sphere by having a rather flat conversion maximum between 5 and 7 s. It can be seen in Fig. 4 that the sharper peak in amplitude response due to the increased radius of the sphere, see Fig. 2, has effects on the power capture ratio. The power capture ratio for the $4 \mathrm{~m}$ radius sphere is much more scattered than for the $3 \mathrm{~m}$ radius sphere and even more if compared to the single cylinder. The power capture ratio decreases with increasing energy periods for the $3 \mathrm{~m}$ radius sphere. This is a desired pattern since it reduces power fluctuations and the mechanical loads on the generator end stop. The single cylinder has no clear peak in the amplitude response (see Fig. 2), and thereby has no sharp increase in power production, but has a flat energy conversion maximum at around $4.5 \mathrm{~s}$. The difference in power capture ratio between the two cases is consistent through all sea states, pointing out the importance of the system to have a wide spectrum for enhanced amplitude response, see Fig. 4.

\section{DISCUSSION}

A key issue for wave energy conversion is to keep the system as simple as possible in order to keep the maintenance cost to a minimum, and this has always been the motto for the Lysekil project. To achieve this, it is important to have as few moving parts as possible. A passive system with an optimized amplitude response has the benefit of few moving parts as compared to a system tuned to optimized wave interference via active control. 
Enhanced amplitude response in the system leads to increased amplitude and speed for the translator movement. The latter can be seen in Fig. 3; the Tb-s has a lower damping coefficient at optimum energy conversion due to the higher speed. Since the converted energy is proportional to the damping coefficient times the speed squared, this leads to the possibility to have smaller units and still keep the same nominal power. Enhanced amplitude response leads to a narrow resonance band width which is in conflict with the desire to have a wide resonance band width for the system to correspond to the wide spectrum of ocean waves. For example, the distinct peak in amplitude response for the Tb-s with $4 \mathrm{~m}$ sphere makes the response more sensitive to the shape of the spectrum and does not lead to a higher overall efficiency. This points out that it is desirable to find a good compromise between a distinct and wide band width for the peak in amplitude response. The increased amplitude and speed will set some increased demands on the generator design. The active length of the translator/stator probably has to be increased, and there is a risk of higher mechanical loads on the generator end stop.

At this stage, viscous damping has been excluded from the calculations. This could lead to predictions of a higher amplitude response at optimum wave interference. The viscous damping may be expected to be larger for the $\mathrm{Tb}$-s than for the single component system due to the increased wetted surface. However, there are indications that in a heavily damped system, the viscous damping is substantially less significant than external damping. ${ }^{25}$ This is expected to be true for this system since the load damping coefficient is approximately $60 \mathrm{kN} \mathrm{s} / \mathrm{m}$.

The differences in power capture ratio between different sea states with the same energy period are greater for the Tb-s, as can be seen in Fig. 4. This can be attributed to the difference in the shape of the spectrum of the sea state. The spectrum of ocean waves is broader than a created spectrum of a fully developed sea and a system with a distinct increase in amplitude response is more sensitive to the shape of the spectrum.

\section{CONCLUSIONS}

A theoretical model for a Tb-s tuned to Swedish west coast wave climate has been developed. The power capture ratio for the $\mathrm{Tb}-\mathrm{s}$ can be increased from $30 \%$ to $60 \%$ at optimum load, compared to a conventional point absorber with one semisubmerged cylinder. The decrease in optimum load damping coefficient from 150 to $60 \mathrm{kN} \mathrm{s} / \mathrm{m}$ opens up the possibility for constructing smaller units with the same nominal power. By changing the radius of the submerged object, the frequency for optimum amplitude response can be tuned to the actual sea state at the site. Further experimental investigation needs to be done regarding the viscous damping from the submerged body; this could also lead to a better insight when choosing the shape of the submerged body. The increased energy conversion could lead to even greater impact on the WEC during extreme forces. The latter is an issue that needs further investigation and even more so in this case with a Tb-s.

\section{ACKNOWLEDGMENTS}

This project was supported by the Swedish Energy Agency, Vattenfall AB, Statkraft AS, Fortum, ÅF Group, The Swedish Association of Graduate Engineers, Seabased AB, Vinnova, Uppsala University, the Gothenburg Energy Research Foundation, Draka Cable AB, the Göran Gustavsson Research Foundation, Vargöns Research Foundation, Falkenberg Energy AB, the Foundation for the Memory of J. Gust Richter, and the Wallenius Foundation. The authors would also like to thank Rafael Waters and Olle Svensson for collecting the wave data. Finally, the authors would like to thank Thomas Götschl, Gunnel Ivarsson, and Christina Wolf for their administrative work.

${ }^{1}$ J. Cruz, Ocean Wave Energy: Current Status and Future Perspectives (Springer-Verlag, Berlin, 2008), pp. 93-104.

${ }^{2}$ A. Clément and P. McCullen, Renewable Sustainable Energy Rev. 6, 405 (2002).

${ }^{3}$ M. Vantorre, Appl. Ocean Res. 26, 61 (2004).

${ }^{4}$ M. Eriksson, R. Waters, O. Svensson, J. Isberg, and M. Leijon, J. Appl. Phys. 102, 084910 (2007).

${ }^{5}$ K. Budar and J. Falnes, Nature (London) 256, 478 (1975).

${ }^{6} \mathrm{~J}$. Falnes, Ocean Waves and Oscillating Systems (Cambridge University Press, Cambridge, 2002), pp. 1-275.

${ }^{7}$ M. T. Pontes, ASME J. Offshore Mech. Arct. Eng. 120, 226 (1998).

${ }^{8}$ J. Falnes, Int. J. Offshore Polar Eng. 12, 147 (2002).

${ }^{9} \mathrm{~V}$. Ferdinande and M. Vantorre, in Hydrodynamics of Ocean Wave-Energy Utilization, IUTAM Symposium, Lisbon, Berlin, edited by D. Evans and A. F. de O. Falcão (Springer, Berlin, 1986), pp. 217-226.

${ }^{10}$ M. Alves, H. Traylor, and A. Sarmento, Proceedings of the Seventh European Wave and Tidal Energy Conference, Porto, Portugal, 2007 (unpublished).

${ }^{11}$ O. Danielsson, M. Eriksson, and M. Leijon, Int. J. Energy Res. 30, 1130 (2006).

${ }^{12}$ M. Leijon, R. Waters, M. Rahm, O. Svensson, C. Boström, E. Strömstedt, J. Engström, S. Tyrberg, A. Savin, H. Gravråkmo, H. Bernhoff, J. Sundberg, J. Isberg, O. Ågren, O. Danielsson, M. Eriksson, E. Lejerskog, B. Bolund, S. Gustafsson, and K. Thorburn, IEEE Power \& Energy Magazine 7, 50 (2009).

${ }^{13}$ J. Engström, R. Waters, M. Stålberg, E. Strömstedt, M. Eriksson, J. Isberg, U. Henfridsson, K. Bergman, J. Asmussen, and M. Leijon, Proceedings of the Seventh European Wave and Tidal Energy Conference, Porto, Portugal, 2007 (unpublished).

${ }^{14}$ R. Waters, M. Stålberg, O. Danielsson, O. Svensson, S. Gustafsson, E. Strömstedt, M. Eriksson, J. Sundberg, and M. Leijon, Appl. Phys. Lett. 90, 034105 (2007).

${ }^{15}$ R. Waters, "Energy from ocean waves," Ph.D. thesis, Uppsala University, 2008.

${ }^{16}$ D. V. Evans, J. Fluid Mech. 77, 1 (1976).

${ }^{17}$ K. Budal, J. Falnes, A. Kyllingstad, and G. Oltedahl, Proceedings of the First Symposium on Wave Energy Utilization, Gothenburg, Sweden, 1980 (unpublished), pp. 253-282.

${ }^{18}$ C.-H. Lee and J. N. Newman, WAMIT ${ }^{\circledR}$, Inc. and Massachusetts Institute of Technology, 1998, http://www.wamit.com.

${ }^{19}$ M. Eriksson, J. Isberg, and M. Leijon, Int. J. Eng. Sci. 43, 1377 (2005).

${ }^{20}$ R. Waters, J. Engström, J. Isberg, and M. Leijon, Renewable Energy 34, 1600 (2009).

${ }^{21}$ P. Ricci, J. B. Saulnier, and A. F. de O. Falcão, Proceedings of the Seventh European Wave and Tidal Energy Conference, Porto, Portugal, 2007 (unpublished).

${ }^{22}$ C. E. Brennen, "A review of added mass and fluid inertial forces," Naval Civil Engineering Laboratory Report No. CR 82.010, 1982.

${ }^{23}$ P. K. Kundu and I. M. Cohen, Fluid Mechanics, 3rd ed. (Elsevier Academic, London, 2004), pp. 200-261.

${ }^{24}$ S. Gustafsson, O. Svensson, J. Sundberg, H. Bernhoff, M. Leijon, O. Danielsson, M. Eriksson, K. Thorburn, K. Strand, U. Henfridsson, E. Eriksson, and K. Bergman, Proceedings of the Sixth European Wave and Tidal Energy Conference, Glasgow, Scotland, 2005 (unpublished).

${ }^{25}$ G. Payne, J. R. M. Taylor, T. Bruce, and P. Parkin, Ocean Eng. 35, 342 (2008). 